\title{
Trends in the Management of Intracranial Vascular Malformations in the USA from 2000 to 2007
}

\author{
Jae H. Choi, ${ }^{1,2}$ John Pile-Spellman, ${ }^{3,4}$ and Jonathan Brisman ${ }^{3}$ \\ ${ }^{1}$ Department of Neurology, Columbia University, New York, NY 10032, USA \\ ${ }^{2}$ Janus Head Consulting, L.L.C., Mineola, NY 11501, USA \\ ${ }^{3}$ Neurological Surgery P.C., Lake Success, NY 11042, USA \\ ${ }^{4}$ Department of Biomedical Engineering, The Fu Foundation School of Engineering and Applied Science, \\ Columbia University, New York, NY 10027, USA
}

Correspondence should be addressed to Jae H. Choi, jae.h.choi.0524@gmail.com

Received 10 September 2011; Accepted 24 November 2011

Academic Editor: Graham S. Venables

Copyright (C) 2012 Jae H. Choi et al. This is an open access article distributed under the Creative Commons Attribution License, which permits unrestricted use, distribution, and reproduction in any medium, provided the original work is properly cited.

\begin{abstract}
Objective. To assess prevalence, clinical characteristics, trends in treatment pattern, and outcome in patients with intracranial vascular malformations (IVMs). Methods. Nationwide inpatient sample. Patients with the diagnosis of an IVM admitted to US hospitals from 2000 to 2007. Results. In 58,051 IVM-related admissions (detection rate 2.4/100,000 person-years; mean age $49 \pm 17$ years; $52 \%$ women) major diagnoses were intracranial hemorrhage ( $\mathrm{ICrH})$ in $15 \%$, seizure $32 \%$, ischemia $5 \%$, and headache $9 \%$. Procedures included surgery (13\%), embolization (13\%), radiation therapy (2\%), aneurysm clipping (1\%), and mechanical ventilation $(6 \%)$. Ventilation and $\mathrm{ICrH}$ were associated with death $(2 \%)$, whereas ventilation, $\mathrm{ICrH}$, surgery, seizure, and ischemia were associated with unfavorable outcome (20\%). IVM detection rate and hospital outcome remained stable over time, whereas mean age and comorbid diagnosis of cerebral ischemia increased ( $\mathrm{ICrH}$ and seizure decreased). Conclusion. IVMs are infrequent and present in $1 / 6$ patients with some form of ICrH. Overall, seizure is the dominant comorbid diagnosis ( $1 / 3$ patients). IVMs are equally prevalent among race-ethnic groups and are increasingly detected later in life. The inpatient care of IVM patients results in death or discharge into specialized care in $1 / 5$ patients.
\end{abstract}

\section{Introduction}

Although relatively infrequent, congenital intracranial vascular malformations (IVMs) represent an important cause of intracranial hemorrhage with potentially devastating consequences for the patient $[1,2]$. Brain arteriovenous malformations (BAVMs) and cavernous malformations (CMs) are the most important forms among IVMs. The detection rate of BAVMs ranges between 1.1-1.4/100,000 personyears and is approximately $2.2 / 100,000$ person-years for all other forms of IVMs, including CM, venous malformation $(\mathrm{VM})$, vein of Galen malformation, and dural AV fistula, respectively [2-4].

Current management of IVMs is an interdisciplinary challenge, involving neurosurgery, interventional neuroradiology, radiation therapy, and neurology. The potentially deleterious effects of IVM-related intracranial hemorrhage
(ICrH) and the risk of recurrent bleeds led to the current paradigm of obliterating the lesion, if deemed feasible with surgery, which appears logical and cause driven [5-7]. In contrast, some large case series found that most patients faired relatively well after the initial hemorrhage from ruptured BAVMs when compared to other causes of $\mathrm{ICrH}$ [8-11]. An ongoing multi center clinical trial, ARUBA, will compare the clinical outcome in patients with unruptured BAVMs randomized either into surgical interventional treatment or medical observation (natural history) $[12,13]$.

Currently, the management patterns vary across centers and may include patients with and without symptoms, with or without intracranial hemorrhage, and with incidentally found IVMs [5]. Specifically, BAVMs often undergo presurgical embolization in an attempt to devascularize the lesion for safer definitive surgery $[6,14]$. Radiation therapy is another adjunct treatment form and also a sole option for 


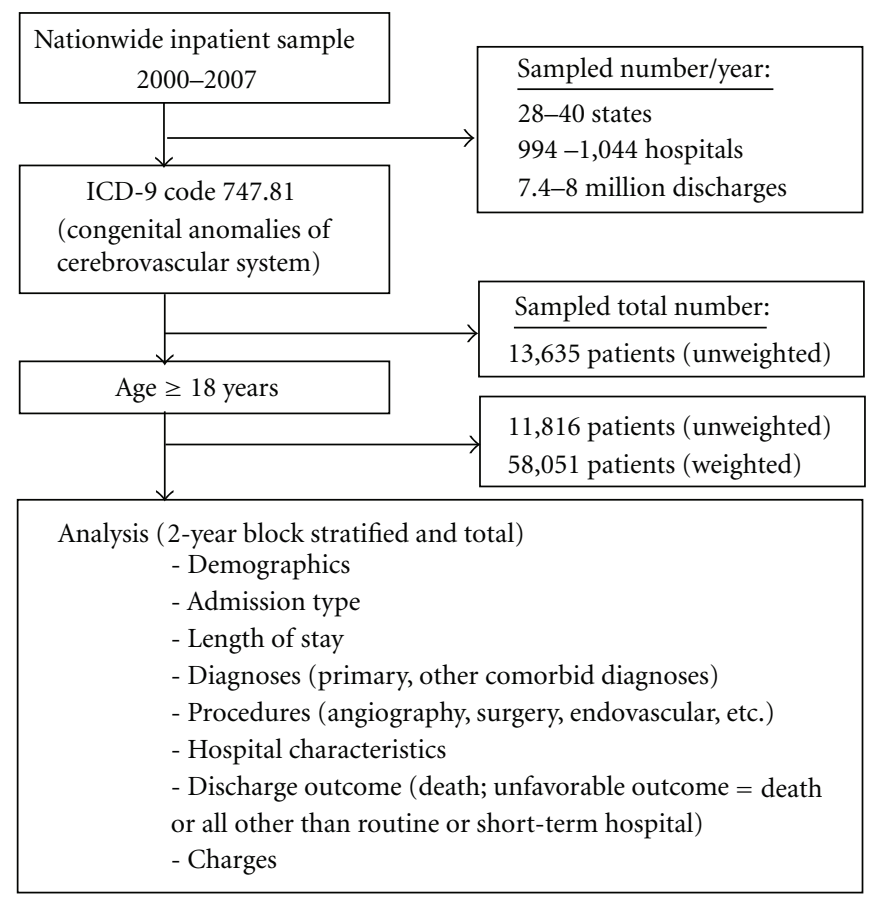

Figure 1: Selection flow chart.

lesions that are otherwise not accessible [14, 15]. Adding to the complexity of the procedures and the overall risk, multiple treatment sessions may be necessary and a small rate of recurrence after angiographically confirmed complete removal has been reported [16]. The goals of the present study are to determine the detection rate of IVMs, to assess patient and clinical characteristics, and to analyze treatment pattern and outcome in patients with IVMs admitted to US hospitals. In addition, a trend analysis is performed on above parameters and on hospital cost using nationwide data from year 2000 to 2007.

\section{Methods}

The Nationwide Inpatient Sample (NIS) is part of the Healthcare Cost and Utilization Project (HCUP) which is sponsored by the Agency for Healthcare Research and Quality (AHRQ) of the US Department of Health \& Human Services and represents the largest all-payer inpatient care database in the USA [17]. Datasets from year 2000 to 2007 were analyzed that included 7.4-8.0 million hospital admissions per year from 28 to 40 states and 994-1,044 nonfederal hospitals, respectively. This constitutes a $20 \%$ representative and stratified sample of US hospitals. The NIS contains only deidentified data.

Variables included demographic parameters, admission type, length of stay, discharge disposition, death, hospital location, and charges. In addition, relevant diagnoses and procedures in the database were identified using the ICD9-CM system (The International Classification of Diseases, 9th Revision, Clinical Modification): adult patients ( $\geq 18$ years) with IVM were selected using code 747.81 (Figure 1). Intracranial hemorrhages were identified using codes 430,
431, and 432.x, seizure using code 345.xx, and headache with 346.xx and 784.0, unruptured cerebral aneurysms with 437.3, and acute ischemic stroke with 433.xx and 434.xx, respectively. Procedures were selected using codes 88.41 (cerebral angiogram), 39.72 and 39.79 (embolization), 01.59 (surgery), 92.3x (radiosurgery), 39.5x (aneurysm clipping), and $96.7 \mathrm{x}$ (mechanical ventilation). The NIS collects up to 15 diagnoses and procedures for each admission. Thus, relevant modes of presentation, including intracranial hemorrhage, seizure, and headache were identified by selecting primary diagnoses only in addition to diagnoses found at "ANY" rank.

Analyses were weighted with provided discharge weight data that are used to create national estimates. For the trend analysis data were stratified into four two-year blocks. Univariate analyses included frequency (absolute number and $\%$ ) and average values (SD; standard deviation) with respective comparative analyses ( $\chi^{2}$-test, $t$-test for independent samples). In multivariate logistic regression models, the risk (odds ratio and 95\% confidence interval; OR 95\%CI) of death and unfavorable discharge outcome (death or discharge, other than routine or to short-term hospital) was determined with input of significant and relevant variables from the univariate analysis. In addition, outcome was assessed for patients presenting with hemorrhage versus without. Outcome was further stratified into one group undergoing surgery and the other without surgery. Furthermore, factors were determined that were associated with hospital charges in multivariate linear regression models. A statistical test was considered significant when $P<0.05$. All statistics were calculated with SPSS 15.0 (Chicago, IL). 


\section{Results}

3.1. Detection Rate. In the years from 2000 to 2007 a total of 58,051 admissions included the diagnosis of an IVM (Table 1 ). This is approximately $0.02 \%$ of all admission (total number of admissions $n=306,447,670$ ) and results in an annual hospital detection rate of approximately 2.4 IVM patients per 100,000 person-years in the US (average USA population 300 Million).

3.2. Patient Characteristics and Clinical Variables. Most admissions were acute admissions (63\%) (Table 1). In average the primary diagnosis was $\mathrm{ICrH}$ in $11 \%$, headache, seizure, or cerebral ischemia in $13 \%$, IVM in $46 \%$, and $31 \%$ had other primary diagnoses. However, 28,760 (35\%) patients had none of the typical "symptoms," including $\mathrm{ICrH}$, seizure, headache, or cerebral ischemia.

3.3. Procedures and Outcome. The most frequent procedure was cerebral angiogram with $37 \%$, followed by embolization and surgery with $13 \%$ in each category (Table 1). In $72 \%$ none of above procedures was performed. Mechanical ventilation was necessary in $6 \%$ of the admissions. The average length of stay was $6 \pm 8$ days. In-hospital death occurred in $2 \%$ of the patients and unfavorable outcome, including death and outcome other than routine or shortterm hospital, was observed in $20 \%$.

3.4. Risk of Death and Unfavorable Outcome. A total of 19 variables were studied for their association with outcome in IVM patients (Table 2). The variables were chosen based on statistical significance in the univariate analysis and based on their potential relevance in having an effect on outcome. Overall, mechanical ventilation (OR 20.3 [95\%-CI 15.027.3]) and $\mathrm{ICrH}(\mathrm{OR} 2.9$ [2.3-3.8]) were strongly associated with in-hospital death (Table 2). Unfavorable discharge outcome showed strong positive associations with ventilation (OR 2.8 [2.4-3.2]), ICrH (OR 2.1 [1.8-2.3]), seizure (OR 1.6 [1.5-1.7]), acute ischemic stroke (OR 1.5 [1.4-1.8]), surgery (OR 1.4 [1.2-1.6]), and unruptured ICA-aneurysm (OR 1.4 [1.1-1.7]).

\subsection{Hemorrhagic Presentation and Surgery}

3.5.1. Hemorrhagic versus Nonhemorrhagic Presentation. Compared with patients with $\mathrm{ICrH}$, patients without bleeds were younger, more frequently women and White, were more often elective admissions, and presented more often with ischemia, seizure, or headache, underwent more endovascular and radiosurgical interventions, and had a shorter length of stay and better outcomes (Table 3/Figures 2(a) and 2(b)).

3.5.2. Hemorrhagic Presentation: Surgery versus No Surgery. From 6,144 patients with ICrH 12.1\% $(n=745)$ underwent surgery. Compared with patient who did not undergo surgery, patients with surgery were less frequently White, but more often Asian, more often elective admissions, had more parenchymal bleeds and ischemia, longer length of stay, and worse outcomes (Table 3/Figures 2(a) and 2(b)).
3.5.3. Nonhemorrhagic Presentation: Surgery versus No Surgery. From 51,873 patients without ICrH $13.1 \%(n=$ 6,697 ) underwent surgery. Compared with patient who did not undergo surgery, patients with surgery were younger, less frequently White or Black, but more often Hispanic, more often elective admissions, had less frequently ischemia or headache, endovascular treatment or radiosurgery, but underwent more often aneurysm clipping, had longer length of stay, and worse outcomes (Table 3/Figures 2(a) and 2(b)).

3.6. Cost. Hospital charges (Figure 3) increased from an average charge of $\$ 32,355 \pm 43,442$ per admission in $2000 / 2001$ to an average of $\$ 51,398 \pm 16412$ in $2006 / 2007$. The total charge increased from $\$ 415,876,303$ in $2000 / 2001$ to $\$ 843,533,680$ in $2006 / 2007$ during this period. This equals an absolute increase of $\$ 427,657,377$ and a relative increase by $103 \%$.

A total of 23 variables were included to determine the association with hospital charges (Table 4). Major determinants included length of stay, number of procedures, embolization, and surgery $\left(r^{2}=0.66 ; P<0.001\right)$. In a second model only 8 variables were included that revealed similar results as the first model, but included "time" as a major determinant $\left(r^{2}=0.62 ; P<0.001\right)$. The overall cost-tocharge ratio was 0.5 .

3.7. Trend Analysis. Over time there was an increase in the number of IVM-related admissions, average age, proportion of women, proportion of acute admissions, and number of diagnoses per patient. Frequencies of cerebral ischemia (stroke and TIA) and headache increased, whereas the incidence of $\mathrm{ICrH}$ and seizure showed a downward trend. Except for embolization, all other operative procedures were performed less frequently over time. Although in-hospital death rate remained stable, the proportion of unfavorable discharge outcome increased over time.

3.8. Comparison with Population Estimates. Data from the US Census 2000 showed similar population distribution pattern compared with the NIS IVM sample: North-East $18.3 \%$ (versus $19.1 \%$ ), Midwest $22.1 \%$ (versus $22.2 \%$ ), South 36.4 (versus 34\%), and West 23.2\% (24.7). The distribution of rural, urban, and urban academic centers were similar across all four US regions (Figure 4). The racial-ethnic distributions in the NIS IVM-sample match the data from the US Census 2000 (Figure 5).

\section{Discussion}

4.1. Epidemiology and Clinical Features. Based on the average frequency of $\mathrm{ICrH}$ of $11 \%$ as the primary diagnosis and assuming $50-62 \%$ of adult BAVM patients present without hemorrhage initially $[3,11]$, the crude estimate of "incidental" BAVMs would be approximately $22-27 \%$ of the NIS IVM sample, that is, approximately 1600-2000 patients per year. With consideration of multiple admissions-the NIS does not allow the identification of multiple admissions-BAVMrelated admissions may be much higher. Among other IVMs than AVMs, cerebral CMs and VMs (often associated with 
TABLE 1: Univariate statistics.

\begin{tabular}{|c|c|c|c|c|c|c|}
\hline $\begin{array}{l}\text { Year } \\
\text { Number of IVM-related admissions }\end{array}$ & $\begin{array}{l}2000 / 2001 \\
n=13,500\end{array}$ & $\begin{array}{l}2002 / 2003 \\
n=14,242\end{array}$ & $\begin{array}{l}2004 / 2005 \\
n=13,331\end{array}$ & $\begin{array}{l}2006 / 2007 \\
n=16,977\end{array}$ & $P$ & $\begin{array}{c}\text { Total } \\
58,051\end{array}$ \\
\hline Total number of admissions & $73,605,206$ & $76,024,680$ & $77,825,620$ & $78,992,164$ & & $306,447,670$ \\
\hline Age, years (SD) & $48.3(17.1)$ & $47.8(17.4)$ & $49.2(17.2)$ & $50.1(17.3)$ & $<0.001$ & $48.9(17.3)$ \\
\hline Women (\%) & 51.5 & 51.8 & 51.7 & 54.2 & $<0.001$ & 52.4 \\
\hline Admission type (\%) & & & & & $<0.001$ & \\
\hline Emergent & 42 & 39.7 & 49.5 & 51 & & 46 \\
\hline Urgent & 18.1 & 18.3 & 15.6 & 15.9 & & 16.9 \\
\hline Elective & 39.9 & 41.8 & 34.5 & 32.8 & & 37 \\
\hline Emergent and urgent & 60.1 & 58 & 65.1 & 66.9 & & 62.9 \\
\hline Disposition (\%) & & & & & $<0.001$ & \\
\hline Routine & 74.7 & 77.5 & 74.1 & 72.8 & & 74.7 \\
\hline Short-term hospital & 5 & 3.7 & 4.1 & 4.6 & & 4.4 \\
\hline Another type facility & 13.4 & 11.2 & 11.9 & 13.4 & & 12.5 \\
\hline Home health care & 4.7 & 4.9 & 6.3 & 6.5 & & 5.7 \\
\hline Against medical advice & 0.3 & 0.6 & 1.1 & 0.8 & & 0.7 \\
\hline Died & 1.9 & 2 & 2.4 & 1.8 & 0.005 & 2 \\
\hline Bad outcome* & 20.3 & 18.7 & 21.7 & 22.5 & $<0.001$ & 20.9 \\
\hline Length of stay, days & $5.9(8.2)$ & $5.4(8.3)$ & $5.4(7.2)$ & $5.4(8.8)$ & $<0.001$ & $5.5(8.2)$ \\
\hline Number of diagnoses, any & $4.9(3.1)$ & $5.2(3.3)$ & $5.9(3.5)$ & $6.8(4.2)$ & $<0.001$ & $5.8(3.6)$ \\
\hline Number of procedures, any & $2.0(2.1)$ & $1.9(2.0)$ & $1.8(2.0)$ & $2.0(2.4)$ & $<0.001$ & $2.0(2.2)$ \\
\hline Race & & & & & $<0.001$ & \\
\hline White & 69.0 & 67.9 & 69.6 & 64.3 & & 67.5 \\
\hline Black & 10.9 & 12.1 & 12.1 & 12.4 & & 11.9 \\
\hline Hispanic & 11.9 & 13.0 & 12.0 & 15.6 & & 13.2 \\
\hline Asian & 4.7 & 3.3 & 3.0 & 3.4 & & 3.6 \\
\hline Native American & 0.3 & 0.3 & 0.3 & 1.1 & & 0.5 \\
\hline Other & 3.1 & 3.3 & 3.0 & 3.2 & & 3.1 \\
\hline \multicolumn{7}{|l|}{ Specific diagnosis all ranks } \\
\hline Any ICrH & 17.5 & 14.0 & 14.8 & 13.7 & $<0.001$ & 14.9 \\
\hline SAH & 5 & 4.0 & 4.3 & 4.5 & 0.001 & 4.4 \\
\hline $\mathrm{ICH}$ & 11.9 & 9.2 & 9.5 & 8.4 & $<0.001$ & 9.7 \\
\hline Other ICrH & 1.4 & 1.5 & 1.6 & 1.8 & 0.068 & 1.6 \\
\hline Seizure & 33.8 & 32.5 & 30.0 & 31.1 & $<0.001$ & 31.8 \\
\hline Headache & 7.1 & 7.8 & 10.1 & 11.7 & $<0.001$ & 9.3 \\
\hline Acute ischemic stroke & 5.9 & 6.1 & 7.2 & 7.9 & $<0.001$ & 6.8 \\
\hline TIA & 2.1 & 2.1 & 2.7 & 3.1 & $<0.001$ & 2.5 \\
\hline Primary specific diagnosis only & 72.1 & 71.6 & 66.5 & 65.2 & $<0.001$ & 68.6 \\
\hline Any ICrH & 12.6 & 9.3 & 11.4 & 9.4 & $<0.001$ & 10.6 \\
\hline Seizure & 5.7 & 5.1 & 5.6 & 7.0 & $<0.001$ & 5.9 \\
\hline Headache & 1.4 & 1.5 & 2.4 & 1.9 & $<0.001$ & 1.8 \\
\hline Acute cerebral ischemia & 2.4 & 2.4 & 3.5 & 4.1 & $<0.001$ & 3.1 \\
\hline TIA & 1.6 & 1.5 & 1.7 & 2.0 & 0.004 & 1.7 \\
\hline IVM & 48.4 & 51.8 & 41.9 & 40.8 & $<0.001$ & 45.5 \\
\hline Intracranial ICA aneurysm, unruptured & 2.5 & 2.7 & 2.8 & 2.7 & 0.305 & 2.7 \\
\hline \multicolumn{7}{|l|}{ Procedures } \\
\hline Cerebral angiogram & 39.7 & 38.8 & 34.8 & 34.9 & $<0.001$ & 37.0 \\
\hline Embolization & $一^{\dagger}$ & 15.5 & 17.4 & 18.4 & $<0.001$ & 13.4 \\
\hline
\end{tabular}


TABle 1: Continued.

\begin{tabular}{lcccccc}
\hline Year & $2000 / 2001$ & $2002 / 2003$ & $2004 / 2005$ & $2006 / 2007$ & $P$ & Total \\
Number of IVM-related admissions & $n=13,500$ & $n=14,242$ & $n=13,331$ & $n=16,977$ & 58,051 \\
\hline \multicolumn{1}{c}{ Surgery } & 14.9 & 12.9 & 11.3 & 12.3 & $<0.001$ \\
Radiosurgery & 2.5 & 3.3 & 1.4 & 0.7 & $<0.001$ & 1.9 \\
Aneurysm clipping & 1.9 & 1.3 & 1.2 & 1.2 & $<0.001$ \\
Embolization, and surgery & 0.1 & 1.2 & 1.6 & 2.5 & $<0.001$ \\
No procedure & 80.1 & 68.6 & 70.8 & 70.2 & $<0.001$ & 72.2 \\
Mechanical ventilation, all durations & 5.4 & 4.8 & 5.8 & 5.9 & $<0.001$ & 5.5 \\
$<96$ hours & 3.2 & 2.5 & 3.4 & 3.9 & $<0.001$ & 3.3 \\
$\geq 96$ hours & 2.4 & 2.3 & 2.4 & 2.0 & 0.057 & 2.3 \\
\hline
\end{tabular}

${ }^{*}$ Death, another type facility, or home health care. ${ }^{\dagger} 1 \%$, misrepresentative figure, likely due to false or not coding. Standard deviation in parenthesis. Abbreviations: ICrH: intracranial hemorrhage, SAH: subarachnoid hemorrhage, ICH: intracerebral hemorrhage, TIA: transient ischemic attack, IVM: intracranial vascular malformation, ICA: internal carotid artery.

TABLE 2: Risk of Death and Unfavorable Outcome*.

\begin{tabular}{|c|c|c|c|c|c|c|}
\hline & \multicolumn{3}{|c|}{ Death } & \multicolumn{3}{|c|}{ Unfavorable Outcome } \\
\hline & OR & $95 \%-C I$ & $P$ & OR & $95 \%-C I$ & $P$ \\
\hline Age & 1.02 & $(1.02-1.03)$ & $<0.001$ & 1.04 & $(1.04-1.04)$ & $<0.001$ \\
\hline Elective admission & 0.65 & $(0.47-0.90)$ & 0.010 & 0.82 & $(0.75-0.90)$ & $<0.001$ \\
\hline Women & 1.16 & $(0.93-1.45)$ & 0.191 & 1.11 & $(1.03-1.20)$ & 0.005 \\
\hline Length of stay & 0.96 & $(0.95-0.97)$ & $<0.001$ & 1.08 & $(1.07-1.08)$ & $<0.001$ \\
\hline Number of procedures & 1.13 & $(1.07-1.19)$ & $<0.001$ & 1.06 & $(1.03-1.08)$ & $<0.001$ \\
\hline White race & 1.07 & $(0.84-1.37)$ & 0.585 & 0.99 & $(0.90-1.07)$ & 0.738 \\
\hline $\mathrm{ICrH}$, any type & 2.93 & $(2.27-3.80)$ & $<0.001$ & 2.06 & $(1.85-2.30)$ & $<0.001$ \\
\hline Seizure & 1.33 & $(1.05-1.68)$ & 0.020 & 1.59 & $(1.46-1.72)$ & $<0.001$ \\
\hline Headache & 0.25 & $(0.10-0.59)$ & 0.002 & 0.70 & $(0.60-0.81)$ & $<0.001$ \\
\hline ICA aneurysm, unruptured & 1.91 & $(1.08-3.40)$ & 0.027 & 1.38 & $(1.09-1.74)$ & 0.007 \\
\hline Acute cerebral ischemia & 0.98 & $(0.65-1.49)$ & 0.942 & 1.55 & $(1.36-1.76)$ & $<0.001$ \\
\hline Cerebral angiography & 0.27 & $(0.20-0.37)$ & $<0.001$ & 0.62 & $(0.56-0.69)$ & $<0.001$ \\
\hline Embolization & 1.54 & $(1.00-2.35)$ & 0.049 & 0.90 & $(0.77-1.04)$ & 0.163 \\
\hline Surgery & 1.04 & $(0.74-1.46)$ & 0.834 & 1.38 & $(1.21-1.58)$ & $<0.001$ \\
\hline Radiosurgery & 0.00 & - & 0.994 & 0.50 & $(0.31-0.81)$ & 0.005 \\
\hline Aneurysm clipping & 0.47 & $(0.18-1.20)$ & 0.115 & 0.44 & $(0.31-0.62)$ & $<0.001$ \\
\hline Ventilation & 20.26 & $(15.01-27.34)$ & $<0.001$ & 2.77 & $(2.37-3.25)$ & $<0.001$ \\
\hline Hospital bed size & 1.13 & $(1.00-1.29)$ & 0.057 & 1.07 & $(1.02-1.12)$ & 0.002 \\
\hline Hospital location/teaching & 0.94 & $(0.81-1.09)$ & 0.397 & 1.07 & $(1.01-1.12)$ & 0.016 \\
\hline
\end{tabular}

${ }^{*}$ Goodness of fit model summary: Death (Nagelkerke $R^{2}=0.342$ ), Unfavorable Outcome (Nagelkerke $R^{2}=0.281$ ).

Abbreviations: 95\%-CI: 95\% Confidence Interval, ICrH: intracranial hemorrhage, ICA: internal carotid artery.

each other) are more frequent, but relatively benign diseases that may present with signs of new or old hemorrhage previously left undetected due to lacking symptoms $[18,19]$. Vein of Galen malformations are prevalent in childhood and AV fistula mostly present without a bleed [20].

The ICD-9 coding system is not specific in terms of type of congenital cerebrovascular malformation. Thus, the estimate on the incidence and prevalence of IVM subtypes can only be crude. However, our estimate on the average annual detection rate of 2.24 IVMs per 100,000 patientyears is similar to findings from previous population-based studies, such as from Olmsted County in Minnesota [21] and the New York Islands [3], USA, and Scotland [2], UK. Hereby, detection rates for BAVMs range from 1.11-1.34 per 100,000 person-years, for CMs from $0.17-0.57$ per 100,000 person-years, for VMs from $0.41-0.44$ per 100,000 personyears, for dural AVMs from $0.15-0.16$ per 100,000 personyears, and for all IVMs from $1.82-2.3$ per 100,000 personyears.

With increasing utilization of brain imaging, such as CT and MRI, more IVMs are found incidentally than before [3, 19]. However, symptoms, including seizure, headache, focal and global neurological deficits, and tinnitus, among others, account for the detection of a significant proportion of 


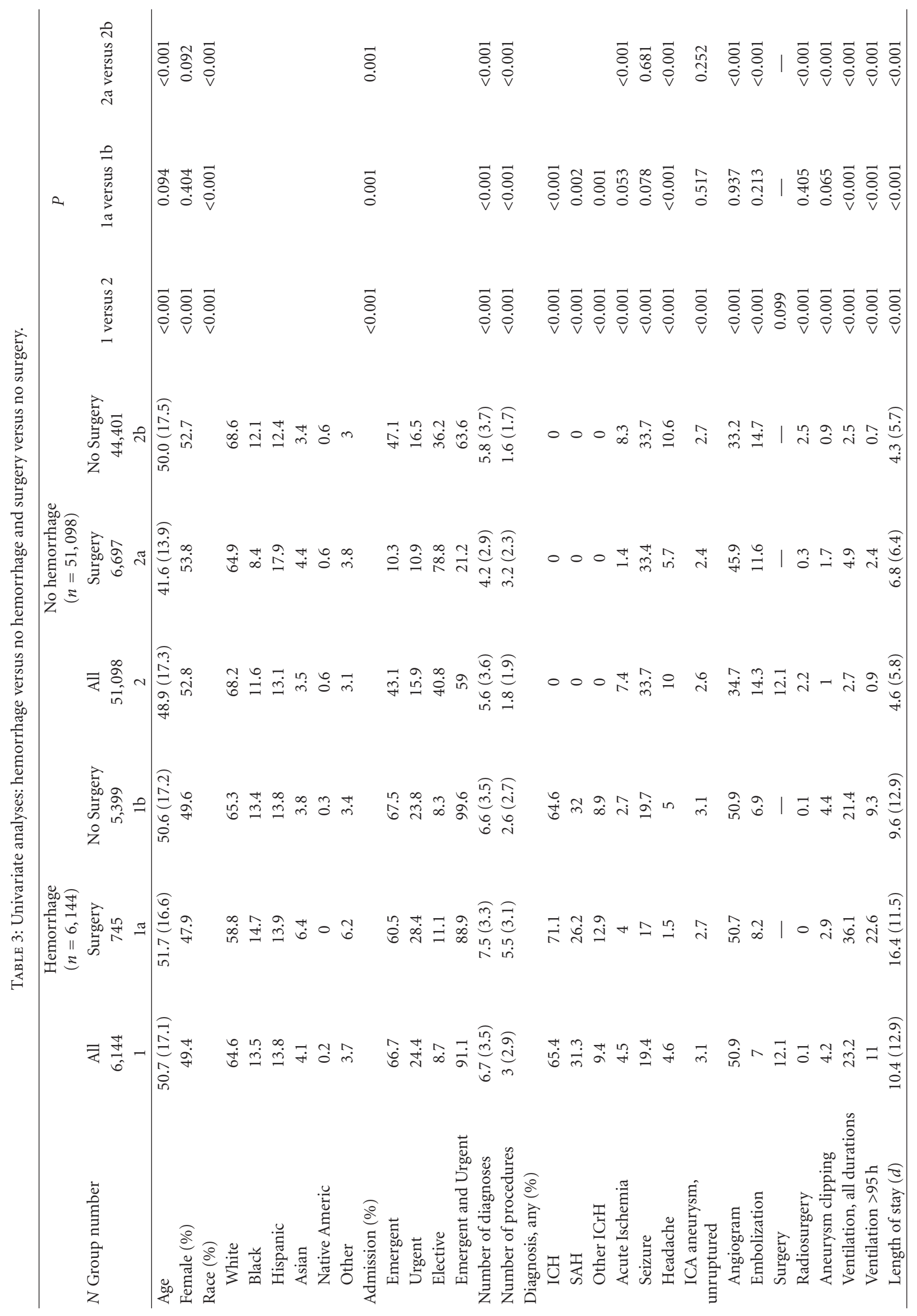




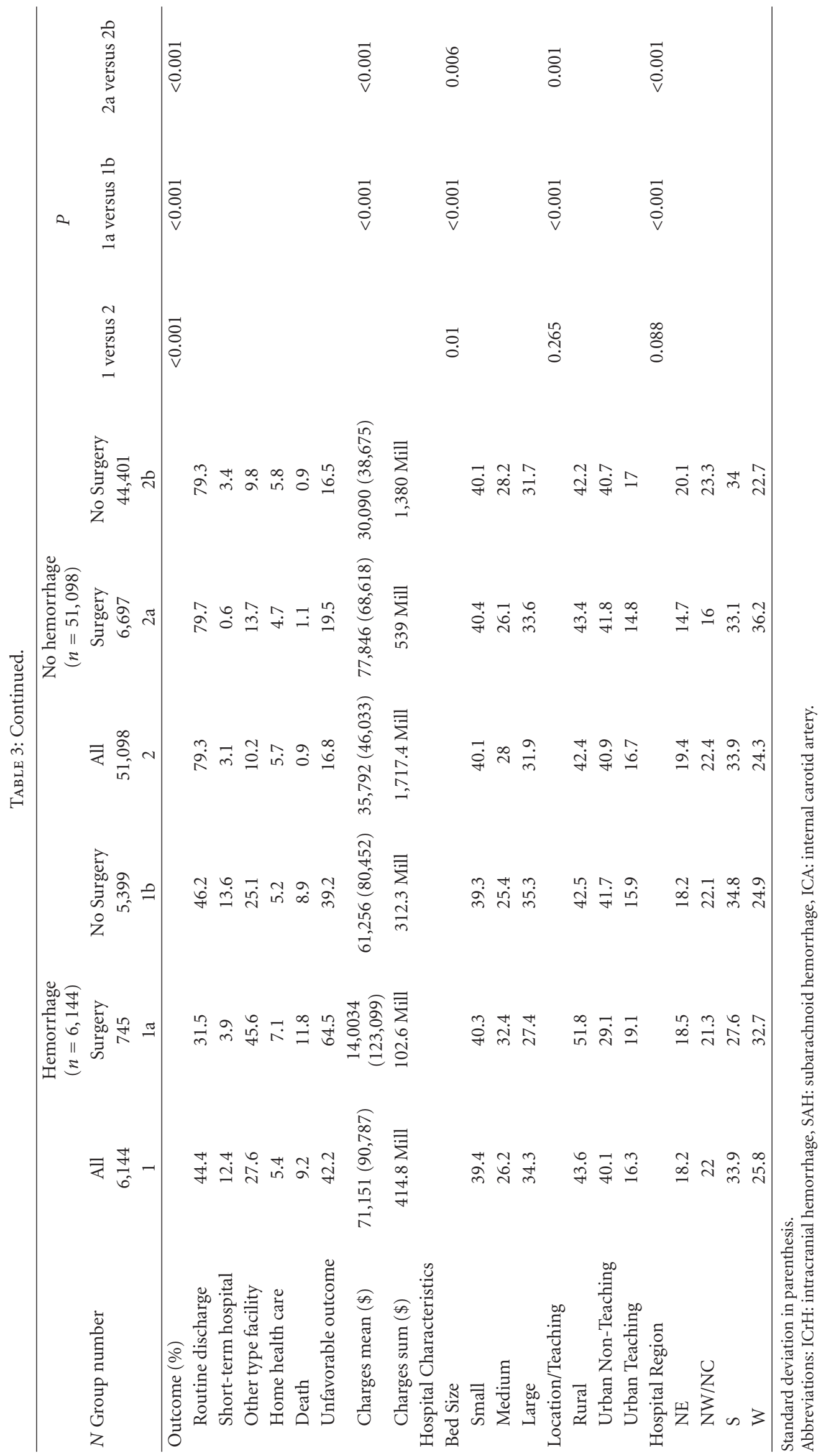




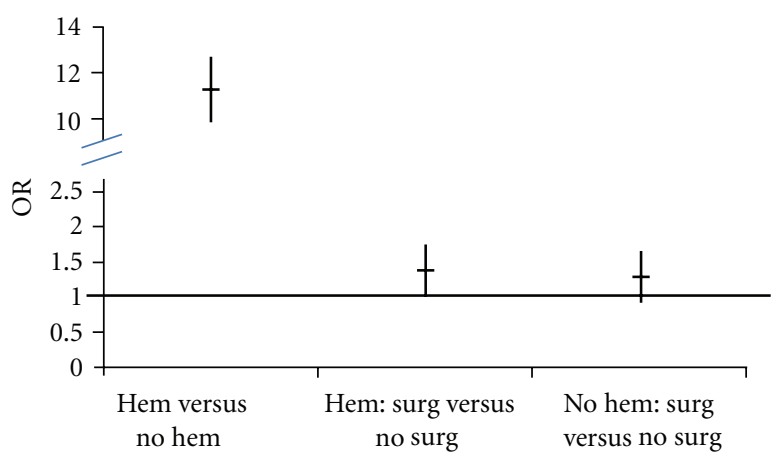

(a)

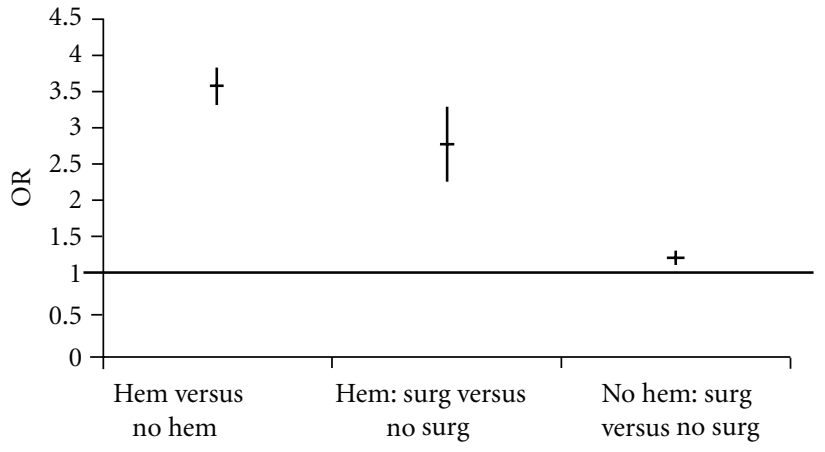

(b)

Figure 2: (a) Risk of death. (b) Risk of unfavorable outcome.

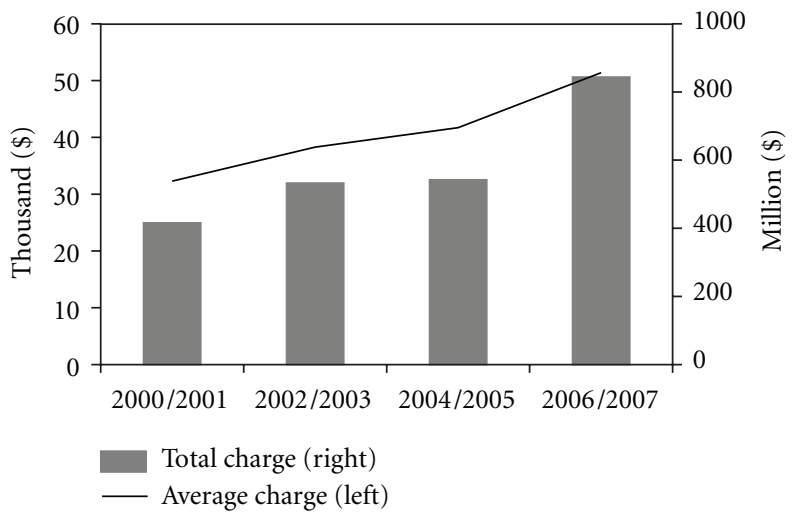

Figure 3: Cost of IVM treatment.

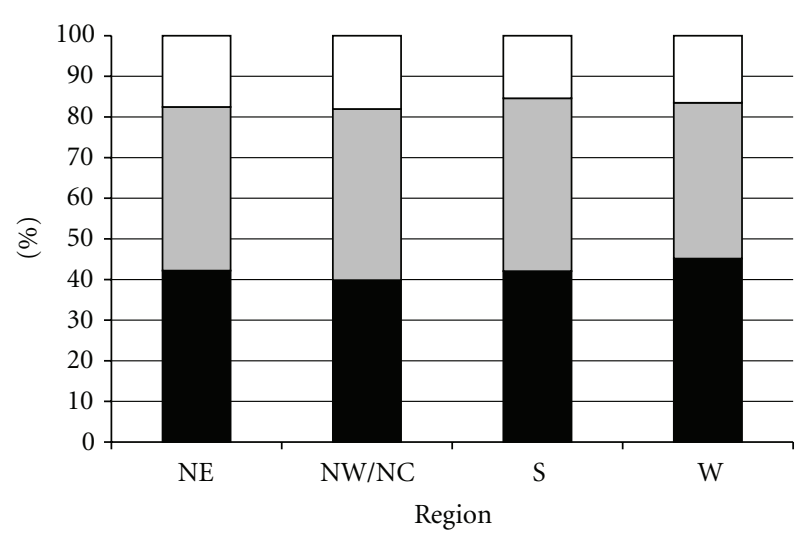

- Rural

$\square$ Urban nonteaching

$\square$ Urban teaching

FIGURE 4: US geographic distribution of different types of hospitals in the NIS IVM sample.

BAVMs (79-85\%), CMs (40-43\%), VMs (7-14\%), and dural AV fistulas (85-100\%) [2, 21]. Prospective studies found that patients with BAVMs presented with $\mathrm{ICrH}$, seizure, headache, and focal neurological deficits in 38-71\%, 24$40 \%, 5-14 \%$, and 5-20\%, respectively [22-25]. When our findings on the frequency of $\mathrm{ICrH}(11 \%)$, seizure $(6 \%)$,

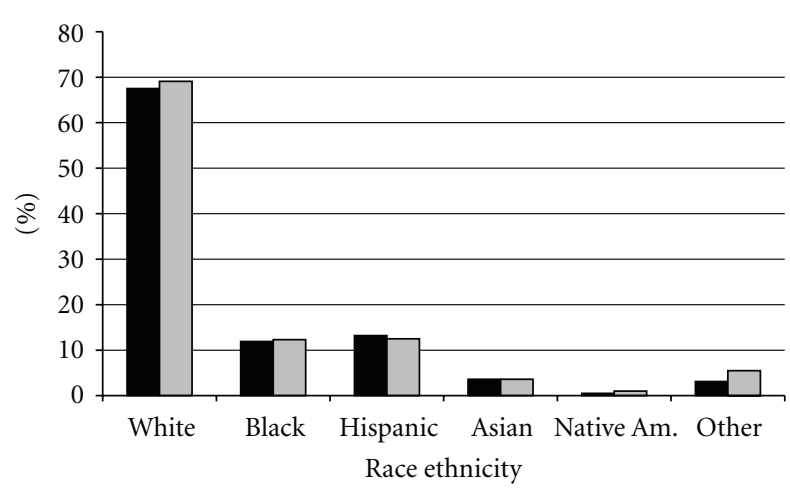

- NIS 2000-2007

口 US Census 2000

FIgURE 5: Racial and ethnic distribution.

headache (2\%), and cerebral ischemia (5\%) are translated into relative proportions, they result in $46 \%, 25 \%, 8 \%$, and $21 \%$, respectively.

4.2. Treatment and Outcome. The multivariate analyses showed that mechanical ventilation had the highest association with death or unfavorable outcome. A plausible way of interpretation is that $\mathrm{ICrH}$ and surgery, both with negative associations with outcome, would necessitate intensive medical care like for any patient in a critical condition. However, seizure, ischemic stroke, and unruptured aneurysm were also significantly associated with unfavorable outcome some of which might occur concurrently with hemorrhage, but may also be unrelated to it.

The clinical outcome after BAVM-related hemorrhage appears to be more favorable compared with the outcome after primary intracerebral hemorrhage (ICH) $[8,9]$. Death rates following BAVM-related bleeds range between $0-11 \%$ (versus 50\% after ICH) and short- (30 days) and mediumterm (one year) functional outcome has been observed to be relatively favorable with a median NIHSS score of 1 (versus median NIHSS of 12) and median Rankin Scale (RS) score of 2 (versus median RS of 6), respectively. 
TABLE 4: Determinants of hospital charges.

(a)

\begin{tabular}{|c|c|c|c|c|c|c|c|c|c|c|}
\hline & & & Model 1 & & & & & Model 2 & & \\
\hline & $\begin{array}{l}\text { Unstd. } \\
\text { Coeffi- } \\
\text { cients } B\end{array}$ & $\begin{array}{l}\text { Standard } \\
\text { Error }\end{array}$ & $\begin{array}{c}\text { Std. } \\
\text { coefficients } \beta\end{array}$ & $t$ & $P$ & $\begin{array}{l}\text { Unstd. } \\
\text { Coeffi- } \\
\text { cients } B\end{array}$ & $\begin{array}{l}\text { Standard } \\
\text { Error }\end{array}$ & $\begin{array}{c}\text { Std. } \\
\text { coefficients } \beta\end{array}$ & $t$ & $P$ \\
\hline Age $(y)$ & 61.48 & 11.49 & 0.0200 & 5.3514 & 0.00000 & & & & & \\
\hline Elective admission & 1763.74 & 424.92 & 0.0160 & 4.1508 & 0.00003 & & & & & \\
\hline In-hospital death & 12044.56 & 1339.92 & 0.0317 & 8.9890 & 0.00000 & & & & & \\
\hline Women & -669.94 & 351.65 & -0.0063 & -1.9052 & 0.05677 & & & & & \\
\hline Length of stay $(d)$ & 3613.12 & 28.99 & 0.5026 & 124.6288 & 0.00000 & 3412.81 & 22.53 & 0.4535 & 151.5009 & 0.00000 \\
\hline \# Diagnoses & -287.82 & 61.42 & -0.0199 & -4.6863 & 0.00000 & & & & & \\
\hline \# Procedures & 7049.92 & 118.25 & 0.2800 & 59.6181 & 0.00000 & 8824.37 & 92.78 & 0.3215 & 95.1101 & 0.00000 \\
\hline Time (year) & 6169.46 & 232.79 & 0.0888 & 26.5024 & 0.00000 & 5677.02 & 137.73 & 0.1095 & 41.2199 & 0.00000 \\
\hline Median income & 847.15 & 156.29 & 0.0177 & 5.4205 & 0.00000 & & & & & \\
\hline $\mathrm{ICrH}$ & 2804.75 & 931.44 & 0.0182 & 3.0112 & 0.00260 & & & & & \\
\hline $\begin{array}{l}\text { ICA aneurysm, } \\
\text { unruptured }\end{array}$ & 1300.84 & 1135.07 & 0.0039 & 1.1460 & 0.25179 & & & & & \\
\hline Acute ischemia & 530.73 & 693.29 & 0.0026 & 0.7655 & 0.44397 & & & & & \\
\hline Seizure & -60.35 & 414.97 & -0.0005 & -0.1454 & 0.88438 & & & & & \\
\hline Headache & 1414.91 & 636.16 & 0.0082 & 2.2241 & 0.02615 & & & & & \\
\hline Angiography & 1372.53 & 431.61 & 0.0124 & 3.1800 & 0.00147 & & & & & \\
\hline Embolization & 29192.74 & 534.78 & 0.2086 & 54.5888 & 0.00000 & 29502.47 & 473.73 & 0.1707 & 62.2773 & 0.00000 \\
\hline IVM surgery & 26550.75 & 608.40 & 0.1564 & 43.6403 & 0.00000 & 27449.01 & 488.44 & 0.1553 & 56.1973 & 0.00000 \\
\hline Radiosurgery & 27182.37 & 1354.84 & 0.0682 & 20.0632 & 0.00000 & 16798.46 & 1122.82 & 0.0397 & 14.9609 & 0.00000 \\
\hline Aneurysm clip & 27896.46 & 1678.19 & 0.0573 & 16.6230 & 0.00000 & 17164.04 & 1341.84 & 0.0338 & 12.7914 & 0.00000 \\
\hline Ventilation & 12209.90 & 933.97 & 0.0518 & 13.0731 & 0.00000 & & & & & \\
\hline ICrH primary diagn. & 3325.46 & 1054.94 & 0.0187 & 3.1523 & 0.00162 & & & & & \\
\hline $\begin{array}{l}\text { Seizure primary } \\
\text { diagnosis }\end{array}$ & 1473.41 & 787.55 & 0.0068 & 1.8709 & 0.06137 & & & & & \\
\hline $\begin{array}{l}\text { Headache primary } \\
\text { diagnosis }\end{array}$ & 921.68 & 1334.31 & 0.0025 & 0.6908 & 0.48972 & & & & & \\
\hline Constant & -26640.78 & 1063.46 & & -25.0510 & 0.00000 & -17986.64 & 416.53 & & -43.1820 & 0.00000 \\
\hline
\end{tabular}

(b)

\begin{tabular}{|c|c|c|c|c|c|}
\hline & Adjusted $R$ square & df1 & df2 & $\begin{array}{c}\text { Sig. F } \\
\text { Change }\end{array}$ & Durbin-Watson \\
\hline $\begin{array}{l}\text { Model } \\
1\end{array}$ & 0.6648 & 23 & 31610 & 0.0000 & 0.3258 \\
\hline $\begin{array}{l}\text { Model } \\
2\end{array}$ & 0.6161 & 8 & 56205 & 0.0000 & 0.3172 \\
\hline
\end{tabular}

Abbreviations: Unstd.: unstandardized, Std.: standardized, \#: number of, ICrH: intracranial hemorrhage, ICA: internal carotid artery, IVM: intracranial vascular malformation.

Because of the negative associations with outcome and because it is difficult to tell which IVM subtype was treated in our sample, we performed a more thorough analysis based on the presence of $\mathrm{ICrH}$ (primary diagnosis) and on whether surgery was performed or not. Overall, 9\% of the patients with $\mathrm{ICrH}$ died and $42 \%$ had unfavorable discharge outcome. Among patients without hemorrhage $0.9 \%$ died and $17 \%$ had unfavorable outcome. The odds for death and bad outcome were highest with the presence of ICrH. Interestingly, surgery was linked to higher odds for death in patients with bleeds and to higher odds for bad outcome in both, bled and unbled patients. Whether this indicates that the most severely affected patients and challenging IVMs are selected for surgery or whether surgery itself poses a greater risk to the patient, regardless of the integrity of the IVM, cannot be derived from our data. 
This may simply reflect the fact that surgery has a known complication and risk profile that may be offset by a decrease in potential morbidity and mortality from a treated IVM over the remaining life of the individual. Such discounting of the beneficial effects of surgical excision of IVMs in an effort to qualify the finding of surgery as an independent predictor of bad outcome and death is beyond the scope of this analysis. The data may, however, in part reflect the current heterogeneous center-specific management pattern of, specifically, BAVMs which remains a challenge and is subject to ongoing studies $[12,26]$. Ongoing and future studies may and ought to give better insights to the rate and degree of recovery from invasive therapies in unbled patients in order to distinguish temporary from permanent functional deficits. It is, nevertheless, important to note that among patients admitted to US hospitals with the diagnoses of an IVM and ICrH, almost 1/10th will die and 2/5th will either die or be discharged to long-term health care facilities or home with home health care. Even more striking is the fact that among patients with the diagnosis of an IVM and without the presence of $\mathrm{ICrH}$, only $1 \%$ will die, but still almost $1 / 6$ th will either die or be discharged with specialized medical care. Overall, 1/5th of all IVM-related admissions will either die or be discharged with long-term care.

4.3. Trend. The comparison of our results with the US consensus data from 2000 suggests that IVMs are equally distributed among racial and ethnic groups and gender groups. It is interesting, however, that the average age increased from $48 \pm 17$ years to $50 \pm 17$ years over the study period ( 8 years). Assuming stable IVM detection rates [24] this could reflect general aging of the US population and mean that IVMs are now detected later in life. Perhaps, the overall improvement of vascular preventive management, such as treatment of hypertension, smoking cessation, and healthier life style, allows IVMs to remain undetected for a longer period of time. The decrease in the rate of $\mathrm{ICrH}$ may be an indicator for such improvements while the rates for seizure and headache remained relatively stable. However, the rate of cerebral ischemic events increased which might be an age and gender effect outweighing the effects of preventive measures. Also, more patients with IVMs present now in an emergent or urgent setting, that is, less electively. This may indicate that while IVMs remain longer silent, once they become symptomatic the clinical picture is relatively dramatic. The trend in the management of IVMs, however, is less invasive in diagnosis (less frequent cerebral angiograms) and therapy (less frequent surgery, but more endovascular therapy). However, radiation therapy also decreased over time. The latter might be due to the increasing shift of radiation therapy into the outpatient setting which is not part of the NIS.

The cost of inpatient IVM management in the US doubled over the 8 years from approximately $\$ 200$ million in years 2000/2001 to $\$ 400$ million in years $2006 / 2007$. This is a true increase in cost as the cost-to-charge ratio remained stable at approximately 0.5 . Additional factors significantly associated with charges include length of stay, number of procedures, and the main procedures, surgery, and endovascular therapy. In aggregate, the management of nonhemorrhagic patients (primary diagnosis only) accounted for $80 \%$ ( $\$ 1.7$ billion) of the total charges over the study period. With an average of almost $\$ 300$ million of inpatient charges per year, the management of IVMs has economic significance in public health. Not included are costs from the outpatient setting and lost productivity [27].

4.4. Limitations. The main limitation is the fact that the ICD-9 coding system summarizes all IVMs into a single code. It is therefore difficult, if not impossible, to distinguish between IVM subtypes. To alleviate this limitation we performed further selections based on published epidemiological and clinical data (frequency, clinical presentation, and $\mathrm{ICrH}$ ) and by focusing on the primary diagnostic code when analyzing presenting symptoms. In terms of the design, this study is primarily a cross-sectional study. The main disadvantage is that the results can provide only a "snapshot in time" of IVMs and its management. This design is not ideally suited for answering questions related to disease process or for revealing causal relationships between diseases. Second, our study also has characteristics of a case-control study, albeit unmatched, as we compare groups with and without hemorrhage and groups with and without surgery with each other. Other limitations include unidentifiable multiple admissions, incomplete clinical and anatomical data, for example, severity of symptoms, angioarchitecture, laboratory and imaging data, and unknown magnitude of misclassifications. Finally, because the NIS sample represents nationwide inpatient treatment, it may not reflect the true incidence or prevalence of IVMs in the general population.

However, there are also unique advantages of analyzing the NIS, a source with a large number of cases resulting in an impressive database with 6-8 million admissions per year and with its wealth of information. In addition, because of the representative nature of the NIS the "snapshot in time" becomes "the big picture" for USA hospital management of medical conditions which may give unique insides into rare diseases such as IVMs. NIS data is also well suited for hypothesis generation, especially with trend data, that certainly requires proof in well-designed prospective and longitudinal studies. The introduction of ICD-10 will allow better differentiation between the various IVM subtypes.

\section{Conclusions}

IVMs are infrequent, equally prevalent among racial-ethnic, and gender groups and present in $1 / 6$ patients with some form of ICrH. Overall, seizure is the dominant comorbid diagnosis ( $1 / 3$ patients). IVMs are now increasingly detected later in life. The short-term outcome of IVM inpatient care has not markedly changed over almost a decade, resulting in death or discharge into specialized care in $1 / 5$ patients.

\section{Conflict of Interests}

All authors declare that they have no relevant conflicts of interest or financial interests to disclose. J. Pile-Spellman 
is member of the steering committee of the NIH-funded ARUBA trial.

\section{References}

[1] J. H. Choi and J. P. Mohr, "Brain arteriovenous malformations in adults," The Lancet Neurology, vol. 4, no. 5, pp. 299-308, 2005.

[2] R. Al-Shahi, J. J. Bhattacharya, D. G. Currie et al., "Prospective, population-based detection of intracranial vascular malformations in adults: the Scottish Intracranial Vascular Malformation Study (SIVMS)," Stroke, vol. 34, no. 5, pp. 1163-1169, 2003.

[3] C. Stapf, H. Mast, R. R. Sciacca et al., "The New York Islands AVM study: design, study progress, and initial results," Stroke, vol. 34, no. 5, pp. e29-e33, 2003.

[4] R. A. Gabriel, H. Kim, S. Sidney et al., "Ten-year detection rate of brain arteriovenous malformations in a large, multiethnic, defined population," Stroke, vol. 41, no. 1, pp. 21-26, 2010.

[5] J. van Beijnum, J. J. Bhattacharya, C. E. Counsell et al., "Patterns of brain arteriovenous malformation treatment: prospective, population-based study," Stroke, vol. 39, no. 12, pp. 3216-3221, 2008.

[6] I. Linfante and A. K. Wakhloo, "Brain aneurysms and arteriovenous malformations: advancements and emerging treatments in endovascular embolization," Stroke, vol. 38, no. 4, pp. 1411-1417, 2007.

[7] M. G. Hamilton and R. F. Spetzler, "The prospective application of a grading system for arteriovenous malformations," Neurosurgery, vol. 34, no. 1, pp. 2-6, 1994.

[8] J. H. Choi, H. Mast, R. R. Sciacca et al., "Clinical outcome after first and recurrent hemorrhage in patients with untreated brain arteriovenous malformation," Stroke, vol. 37, no. 5, pp. 1243-1247, 2006.

[9] J. van Beijnum, C. E. Lovelock, C. Cordonnier et al., "Outcome after spontaneous and arteriovenous malformation-related intracerebral haemorrhage: population-based studies," Brain, vol. 132, no. 2, pp. 537-543, 2009.

[10] C. Stapf, H. Mast, R. R. Sciacca et al., "Predictors of hemorrhage in patients with untreated brain arteriovenous malformation," Neurology, vol. 66, no. 9, pp. 1350-1355, 2006.

[11] R. Al-Shahi and C. Warlow, "A systematic review of the frequency and prognosis of arteriovenous malformations of the brain in adults," Brain, vol. 124, no. 10, pp. 1900-1926, 2001.

[12] J. P. Mohr, A. J. Moskowitz, C. Stapf et al., "The ARUBA trial: current status, future hopes," Stroke, vol. 41, no. 8, pp. e537e540, 2010.

[13] C. Stapf, J. P. Mohr, J. H. Choi, A. Hartmann, and H. Mast, "Invasive treatment of unruptured brain arteriovenous malformations is experimental therapy," Current Opinion in Neurology, vol. 19, no. 1, pp. 63-68, 2006.

[14] Y. P. Gobin, A. Laurent, L. Merienne et al., "Treatment of brain arteriovenous malformations by embolization and radiosurgery," Journal of Neurosurgery, vol. 85, no. 1, pp. 1928, 1996.

[15] K. Maruyama, N. Kawahara, M. Shin et al., "The risk of hemorrhage after radiosurgery for cerebral arteriovenous malformations," The New England Journal of Medicine, vol. 352, no. 2, pp. 146-153, 2005.

[16] U. Sure, N. Butz, A. M. Siegel, H. D. Mennel, S. Bien, and H. Bertalanffy, "Treatment-induced neoangiogenesis in cerebral arteriovenous malformations," Clinical Neurology and Neurosurgery, vol. 103, no. 1, pp. 29-32, 2001.

[17] HCUP Nationwide Inpatient Sample (NIS). Healthcare Cost and Utilization Project (HCUP). 2000-2007. Agency for Healthcare Research and Quality, Rockville, Md, USA, http://www.hcup-us.ahrq.gov/nisoverview.jsp.

[18] C. W. Washington, K. E. McCoy, and G. J. Zipfel, "Update on the natural history of cavernous malformations and factors predicting aggressive clinical presentation," Neurosurgical Focus, vol. 29, no. 3, p. E7, 2010.

[19] D. S. M. Ruíz, H. Yilmaz, and P. Gailloud, "Cerebral developmental venous anomalies: current concepts," Annals of Neurology, vol. 66, no. 3, pp. 271-283, 2009.

[20] G. J. Zipfel, M. N. Shah, D. Refai, R. G. Dacey, and C. P. Derdeyn, "Cranial dural arteriovenous fistulas: modification of angiographic classification scales based on new natural history data," Neurosurgical Focus, vol. 26, no. 5, p. E14, 2009.

[21] R. D. Brown Jr., D. O. Wiebers, J. C. Torner, and W. M. O'Fallon, "Incidence and prevalence of intracranial vascular malformations in Olmsted County, Minnesota, 1965 to 1992," Neurology, vol. 46, no. 4, pp. 949-952, 1996.

[22] C. Hofmeister, C. Stapf, A. Hartmann et al., "Demographic, morphological, and clinical characteristics of 1289 patients with brain arteriovenous malformation," Stroke, vol. 31, no. 6, pp. 1307-1310, 2000.

[23] H. Mast, W. L. Young, H. C. Koennecke et al., "Risk of spontaneous haemorrhage after diagnosis of cerebral arteriovenous malformation," The Lancet, vol. 350, no. 9084, pp. 1065-1068, 1997.

[24] S. L. Ondra, H. Troupp, E. D. George, and K. Schwab, "The natural history of symptomatic arteriovenous malformations of the brain: a 24-year follow-up assessment," Journal of Neurosurgery, vol. 73, no. 3, pp. 387-391, 1990.

[25] L. da Costa, M. C. Wallace, K. G. ter Brugge, C. O'Kelly, R. A. Willinsky, and M. Tymianski, "The natural history and predictive features of hemorrhage from brain arteriovenous malformations," Stroke, vol. 40, no. 1, pp. 100-105, 2009.

[26] C. J. Wedderburn, J. van Beijnum, J. J. Bhattacharya et al., "Outcome after interventional or conservative management of unruptured brain arteriovenous malformations: a prospective, population-based cohort study," The Lancet Neurology, vol. 7, no. 3, pp. 223-230, 2008.

[27] C. E. Miller, Z. Quayyum, P. Mcnamee, and R. A.-S. Salman, "Economic burden of intracranial vascular malformations in adults: prospective population-based study," Stroke, vol. 40, no. 6, pp. 1973-1979, 2009. 


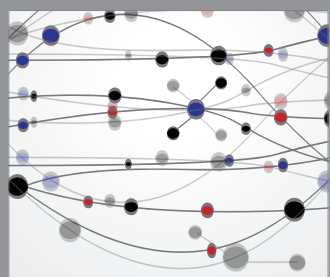

The Scientific World Journal
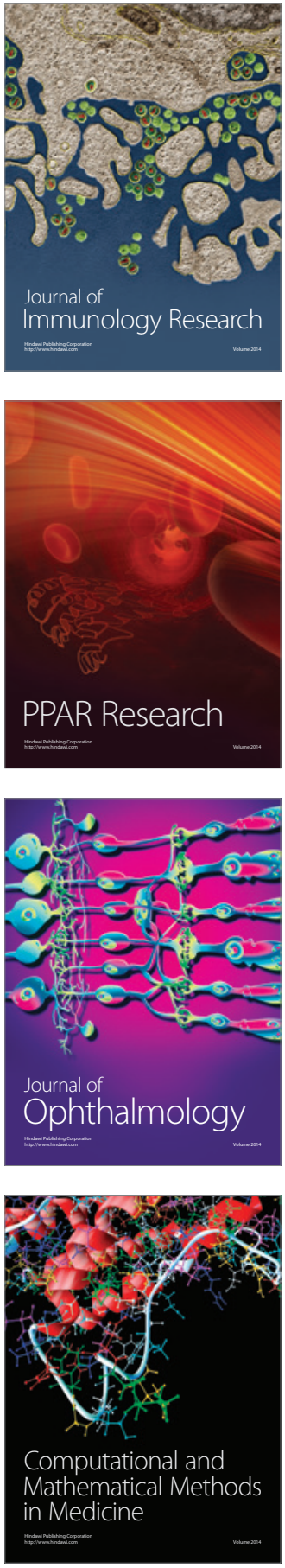

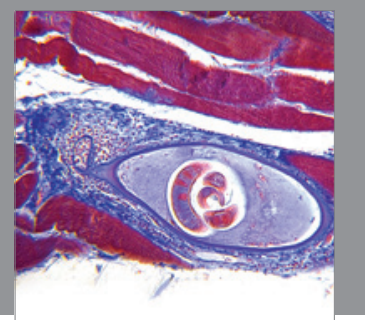

Gastroenterology

Research and Practice
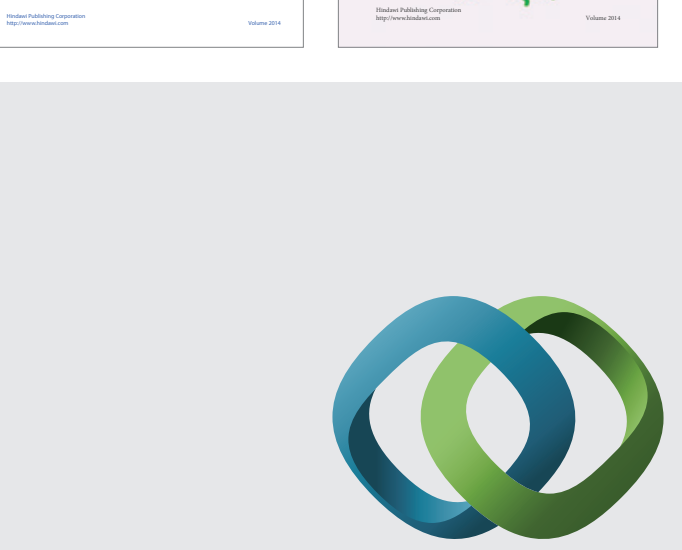

\section{Hindawi}

Submit your manuscripts at

http://www.hindawi.com
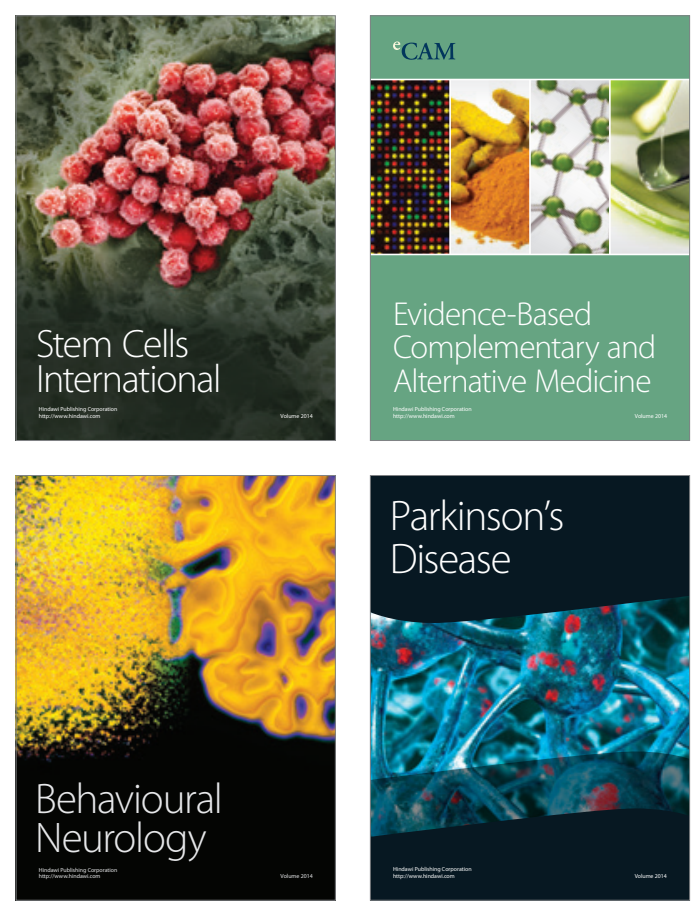

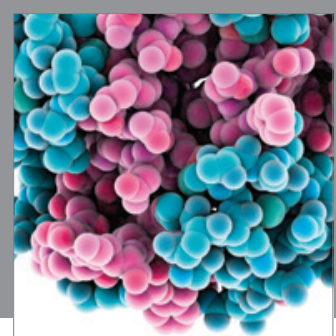

Journal of
Diabetes Research

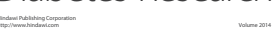

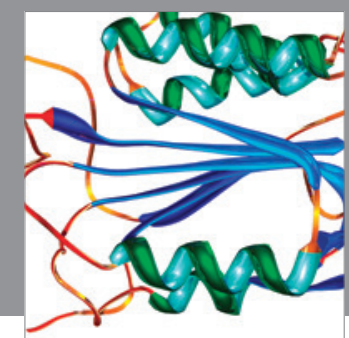

Disease Markers
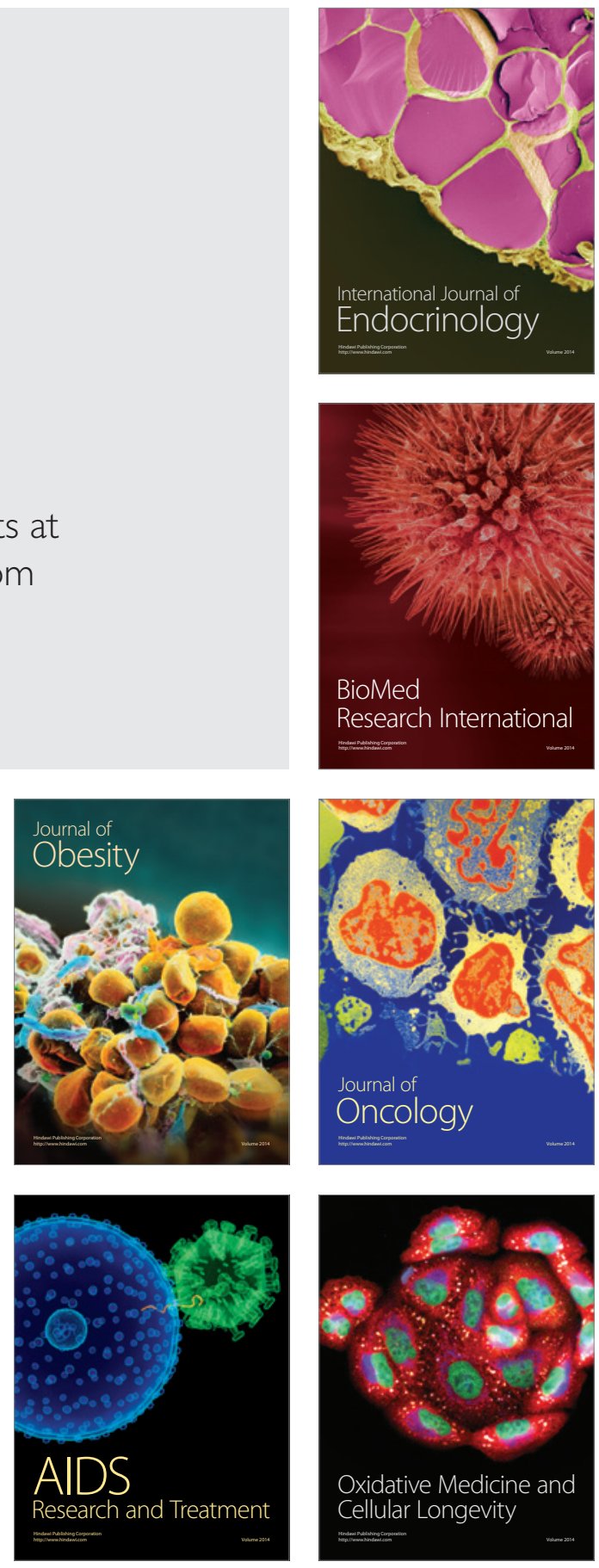